\title{
Gomisin M2 alleviates psoriasis-like skin inflammation by inhibiting inflammatory signaling pathways
}

\author{
NAMKYUNG KIM ${ }^{1 *}$, SOYOUNG LEE ${ }^{2 *}$, JINJOO KANG $^{1}$, TAEG KYU KWON ${ }^{3}$, \\ DONGWOO KHANG ${ }^{4}$ and SANG-HYUN KIM ${ }^{1}$
}

\author{
${ }^{1}$ Department of Pharmacology, School of Medicine, Kyungpook National University, Daegu 41944; ${ }^{2}$ Immunoregulatory \\ Materials Research Center, Korea Research Institute of Bioscience and Biotechnology, Jeongeup, Jeollabuk-do \\ 56212; ${ }^{3}$ Department of Immunology, School of Medicine, Keimyung University, Daegu 42601; ${ }^{4}$ Department \\ of Physiology, School of Medicine, Gachon University, Yeonsu, Incheon 21999, Republic of Korea
}

Received June 5, 2021; Accepted September 22, 2021

DOI: $10.3892 / \mathrm{mmr} .2021 .12499$

\begin{abstract}
Psoriasis, a chronic inflammatory skin disease, is characterized by the excessive proliferation and impaired differentiation of epidermal keratinocytes and is accompanied by the increased infiltration of inflammatory cells. The condition requires long-term treatment and has no definitive cure. Hence, supplements and therapeutic agents have been intensely investigated. Gomisin M2 (GM2), a lignan extracted from Schisandra chinensis (Turcz). Baill. (Schisandraceae; S. chinensis), has demonstrated diverse pharmacological properties, including anticancer, anti-inflammatory and antiallergic effects. Based on these findings, the present study examined the effects of GM2 on an imiquimod (IMQ)-induced psoriasis mouse model and on keratinocytes stimulated by tumor necrosis factor (TNF)- $\alpha$ and interferon- $\gamma$. IMQ was topically
\end{abstract}

Correspondence to: Professor Sang-Hyun Kim, Department of Pharmacology, School of Medicine, Kyungpook National University, 680 Gukchaebosang-ro, Jung, Daegu 41944, Republic of Korea

E-mail: shkim72@knu.ac.kr

Professor Dongwoo Khang, Department of Physiology, School of Medicine, Gachon University, 155 Gaetbeol-ro, Yeonsu, Incheon 21999, Republic of Korea

E-mail: dkhang@gachon.ac.kr

*Contributed equally

Abbreviations: GM2, gomisin M2; IMQ, imiquimod; TNF, tumor necrosis factor; IFN, interferon; MPO, myeloperoxidase; STAT1, signal transducers and activators of transcription 1; NF- $\mathrm{BB}$, nuclear factor- $\kappa \mathrm{B}$; Dexa, dexamethasone; PASI, Psoriasis Area Severity Index; TEWL, transepidermal water loss; RT-qPCR, reverse transcription-quantitative polymerase chain reaction; ELISA, enzyme-linked immunosorbent assay; H\&E, hematoxylin and eosin; IHC, immunohistochemistry; PBS, phosphate buffered saline; GAPDH, glyceraldehyde 3-phosphate dehydrogenase

Key words: gomisin M2, psoriasis, keratinocytes, myeloperoxidase, Th1/Th17 cells applied to the back skin of mice for 7 consecutive days, and the mice were orally administered $\mathrm{CD}$. These results showed that the oral administration of GM2 suppressed the symptoms of psoriasis, as evidenced by reductions in skin thickness, psoriasis area severity index scores for psoriasis lesions, transepidermal water loss and myeloperoxidase (MPO)-associated cell infiltration. Furthermore, GM2 reduced the pathologically increased levels of immunoglobulin G2a, MPO and TNF- $\alpha$ in the serum and T helper (Th)1 and Th17 cell populations in the spleen. GM2 decreased the gene expression of inflammatory-related cytokines and chemokines and inhibited the expression of signal transducer and activator of transcription 1 and nuclear factor- $\mathrm{\kappa B}$ in the activated keratinocytes. These results suggested that GM2 from $S$. chinensis is a potential therapeutic candidate to alleviate psoriasis-like skin inflammation.

\section{Introduction}

Psoriasis is a chronic inflammatory skin disease that affects 2-3\% of the population in the United States, and its prevalence has been increasing over the past few decades $(1,2)$. A lack of understanding exists regarding the mechanisms leading to the increased immunological response in psoriasis, and a complete cure is not available for this disease $(3,4)$. Patients are commonly prescribed steroids for treatment. However, the use of steroids is not recommended by dermatological textbooks and guidelines owing to the high number of side effects (5). Therefore, an effective psoriasis treatment that is devoid of side effects is urgently required (6).

Psoriasis is a T cell-mediated skin inflammatory disorder that is characterized by the hyperproliferation and abnormal differentiation of the epidermal keratinocytes (7). The condition results from the continuous interactions between the infiltrated inflammatory cells and the activated keratinocytes (8). The infiltration of T cells and neutrophils leads to the production of various cytokines, such as interleukin (IL)-17, IL-23 and interferon (IFN)- $\gamma$, which stimulate the keratinocytes and exacerbate psoriasis (9). Moreover, these cytokines activate the signal transducers and activators of transcription 1 (STAT1) and nuclear factor- $\mathrm{\kappa B}(\mathrm{NF}-\mathrm{\kappa B})$ in the psoriatic 
keratinocytes (10). Therefore, pharmacological interventions that effectively suppress the signaling molecules that induce inflammatory mediators are potential targets for the development of therapeutic compounds.

The fruit of Schisandra chinensis (Turcz). Baill. (Schisandraceae; S. chinensis) is a commonly known traditional Chinese herb that is widely used to treat asthma, rheumatism, cough and arthritis $(11,12)$. In addition, S. chinensis has antiallergic, anti-inflammatory, antitumor and antiviral effects $(11,13,14)$. S . chinensis is rich in bioactive components, including lignans, triterpenoids, polysaccharides and sterols (15).

In particular, lignans, which function as antioxidants and play a role in plant defenses, and exhibit anti-inflammatory and antioxidant activities that can be utilized to treat skin diseases (16). Among the lignans, gomisin M2 (GM2) has shown antiallergic effects by inhibiting mast cell activation and the human immunodeficiency virus (17-19).

Although GM2 exerts diverse pharmacological effects, its molecular mechanisms have not been demonstrated in studies on skin inflammatory disorders, particularly psoriasis. Based on the diverse pharmacological effects of GM2 extracted from $S$. chinensis, the present study investigated the anti-inflammatory effects of GM2 on an imiquimod (IMQ)-induced mouse model and keratinocytes.

\section{Materials and methods}

Plant material, isolation of GM2 and reagents. The fruits of $S$. chinensis were purchased from the Yangnyeong Herbal Medicine Market (Daegu, Korea). The fruits $(20 \mathrm{~kg}$ ) were subjected to $95 \%$ ethanol (10 l) extraction at room temperature for 5 days. The ethanolic extract was evaporated in vacuo to yield $5.7 \mathrm{~kg}$ residue, which was resuspended in $\mathrm{H}_{2} \mathrm{O}$ and successively partitioned with dichloromethane, ethyl acetate and n-butanol. The dichloromethane extract (525 g) was then subjected to silica gel column chromatography with a gradient of ether/acetone (20:1 to $1: 2$ ) to obtain five major fractions (Fr. 1-Fr. 5). Fr. 1 was subjected to Sephadex LH-20 elution with methanol/ $\mathrm{H}_{2} \mathrm{O}$ (1:1), yielding two fractions (Fr. 1-1, Fr. 1-2). Medium-pressure liquid chromatography of Fr. 1-1 and Fr. 1-2 eluted with $\mathrm{MeOH} / \mathrm{H}_{2} \mathrm{O}$ (10:1 to $\left.1: 1\right)$ yielded GM2 (64 mg). GM2 was identified by ${ }^{1} \mathrm{H}$ and ${ }^{13} \mathrm{C}$-nuclear magnetic resonance, and the spectral data were compared with published data (20).

The purity of GM2 isolated from S. chinensis was confirmed to be $94.8 \%$ pure by percentage of the peak area of GM2 compared with the total peak area using high-performance liquid chromatography with diode-array detection (Fig. S1A-C), and the analysis conditions are described in Table I. All reagents were purchased from Sigma-Aldrich (Merck KGaA) unless otherwise stated, and recombinant human tumor necrosis factor (TNF)- $\alpha$ and IFN- $\gamma$ were procured from R\&D Systems, Inc.

Ethics statement and cell culture. C57BL/6J female mice (age, 8 weeks old; weight, 18-20 g) were purchased from the Dae-Han Experimental Animal Center (Daejeon, Korea). Throughout the study period, four mice were housed per cage in a laminar air flow room maintained at a temperature of
$23 \pm 2^{\circ} \mathrm{C}$ and a relative humidity of $55 \pm 5 \%$ with 12 -h light/dark cycles. The care and treatment of the mice were performed in accordance with the guidelines established by the Public Health Service Policy on the Humane Care and Use of Laboratory Animals (21). The study protocols were approved by the Institutional Animal Care and Use Committee of Kyungpook National University (approval no. KNU-2019-0001-5; Daegu, Korea).

Human keratinocyte cell line, HaCaT (American Type Culture Collection), were maintained in Dulbecco's modified Eagle's medium (Gibco; Thermo Fisher Scientific, Inc.), supplemented with $10 \%$ fetal bovine serum (Gibco; Thermo Fisher Scientific, Inc.) and antibiotics (100 U/ml penicillin G and $100 \mu \mathrm{g} / \mathrm{ml}$ streptomycin; Gibco; Thermo Fisher Scientific, Inc.) at $37^{\circ} \mathrm{C}$ in $5 \% \mathrm{CO}_{2}$.

Cell viability. To quantify cell viability, human keratinocytes (HaCaT cells) were seeded in 96-well plates at $1 \times 10^{4}$ cells/well. Cells were treated with $\mathrm{CD}$ or CA at $37^{\circ} \mathrm{C}$ for $24 \mathrm{~h}$. A total of $20 \mu \mathrm{l}$ 3-(4,5-dimethylthiazole-2-yl)-2,5-diphenyltetrazolium bromide (MTT) solution $(1 \mathrm{mg} / \mathrm{ml})$ was added to each well. The plates were incubated at $37^{\circ} \mathrm{C}$ for $4 \mathrm{~h}$. The resulting formazan crystals were dissolved using $100 \mu \mathrm{l}$ DMSO per well, and the absorbance was measured using a spectrophotometer (Molecular Devices, LLC) at a wavelength of $570 \mathrm{~nm}$.

IMQ-induced psoriasis-like skin inflammation model and treatment with GM2. To induce psoriasis-like skin inflammation, the hairs present in the back skin of each mouse were removed by shaving. The mice $(n=28)$ were randomly divided into seven groups of four mice each: i) Control [phosphate buffered saline (PBS)]; ii) $10 \mathrm{mg} / \mathrm{kg} \mathrm{GM}$; iii) IMQ + PBS; iv) IMQ + $0.1 \mathrm{mg} / \mathrm{kg}$ GM2; v) IMQ + $1 \mathrm{mg} / \mathrm{kg} \mathrm{GM}$; vi) IMQ + $10 \mathrm{mg} / \mathrm{kg} \mathrm{GM} 2$; and vii) IMQ + $1 \mathrm{mg} / \mathrm{kg}$ dexamethasone (Dexa). IMQ cream (5\%, Aldara ${ }^{\mathrm{TM}}$; Dong-A Pharmaceutical Co., Ltd.), $62.5 \mathrm{mg}$, was applied on the back skin. GM2 and Dexa were dissolved in PBS and orally administrated by gavage for 7 consecutive days. Dexa is used as a first-line treatment for psoriasis and is administered by topical, oral, intravenous or intramuscular injection (22-24). Therefore, Dexa was used as an orally administered positive drug control under the same conditions as GM2 in this study. Based on the use of Dexa $(1 \mathrm{mg} / \mathrm{kg})$ as a positive drug control in various studies (25-27), $1 \mathrm{mg} / \mathrm{kg}$ Dexa was used in this study.

Each day, the following parameters were measured after 24 h: i) Skin thickness; ii) the Psoriasis Area Severity Index (PASI); and iii) transepidermal water loss (TEWL). The back-skin thickness was measured using a dial thickness gauge (Mitutoyo Corporation), whereas TEWL was measured using a gpskin Barrier Light. PASI was estimated using the erythema, scaling and thickness parameters, and was scored independently on a 5-point scale: i) 0 , none; ii) 1 , slight; iii) 2 , moderate; iv) 3, marked; and v) 4, very marked. Skin thickness, TEWL and the PASI score were determined for 7 consecutive days.

To examine the characteristics associated with psoriasis, photographs were taken of the back skin of mice at day 7 . Next, the mice were put into a chamber and then $30 \% \mathrm{vol} / \mathrm{min}$ of $\mathrm{CO}_{2}$ gas was injected into the chamber while controlling the flowmeter at the end of the experiment (7 days). After 
Table I. Conditions of HPLC-DAD.

\begin{tabular}{lc}
\hline Parameters & Conditions \\
\hline Analytical column & $\begin{array}{c}\text { Phenomenex C18 }(4.6 \times 300 \mathrm{~mm}) \\
\text { HPLC system } \\
\text { Detector }\end{array}$ \\
Mobile phase for & Diode Array detector $(200 \sim 500 \mathrm{~nm})$ \\
Solvent A & \\
0 min & 60 \\
30 min & 15 \\
40 min & 15 \\
60 min & 60 \\
Mobile phase for & Methanol, $\%$ \\
Solvent B & \\
0 min & 40 \\
30 min & 85 \\
40 min & 85 \\
60 min & 40 \\
Flow rate, ml/min & 1.0 \\
Column oven & 30 \\
temperature, ${ }^{\circ} \mathrm{C}$ & \\
Injection volume, $\mu 1$ & 20 \\
Run time, min & 60 \\
\hline
\end{tabular}

HPLC-DAD, high-performance liquid chromatography with diode-array detection.

euthanasia, the back skin, spleen and whole blood from the abdominal vena cava were collected. The back skin was used for histological analysis and reverse transcription-quantitative polymerase chain reaction ( $\mathrm{RT}-\mathrm{qPCR}$ ), and the whole blood was centrifuged at $400 \mathrm{x} \mathrm{g}$, for $15 \mathrm{~min}$, at $4^{\circ} \mathrm{C}$ for the enzyme-linked immunosorbent assay (ELISA).

ELISA. The serum levels of immunoglobulin (Ig) G2a (cat. no. 552576; BD Biosciences), TNF- $\alpha$ (cat. no. 558534; BD Biosciences) and myeloperoxidase (MPO; cat. no. DY3667; R\&D Systems, Inc.) were measured using a sandwich ELISA kit as per the manufacturer's protocol. IL-6 (cat. no. DY206; R\&D Systems, Inc.) and CCL17 (cat. no. DY364; R\&D Systems, Inc.) levels in $\mathrm{HaCaT}$ cells were measured using ELISA kits. The cells $\left(2 \times 10^{5}\right.$ cells/well in a 24 -well plate) were pretreated with or without GM2 $(0.1,1$ or $10 \mu \mathrm{M})$ or Dexa $(10 \mu \mathrm{M})$ for $1 \mathrm{~h}$, and then stimulated with TNF- $\alpha(10 \mathrm{ng} / \mathrm{ml})$ and IFN- $\gamma$ $(10 \mathrm{ng} / \mathrm{ml})$ at $37^{\circ} \mathrm{C}$ for $15 \mathrm{~h}$. These supernatants were collected and centrifuged at $400 \mathrm{x}$ g at $4^{\circ} \mathrm{C}$ for $10 \mathrm{~min}$. IL- 6 and CCL17 levels were analyzed in accordance with the manufacturer's instructions. Absorbance was read at $450 \mathrm{~nm}$ using a spectrophotometer (VersaMax; Molecular Devices, LLC). Data analysis was performed SoftMax Pro software version 6 (Molecular devices, LLC).

$R N A$ isolation and $R T-q P C R$. RNA samples were isolated from the HaCaT cells and the mice back skin using the RNAiso Plus kit (Takara Bio, Inc.) as per the manufacturer's protocol. The HaCaT cells $\left(2 \times 10^{5}\right.$ cells/well in a 24 -well plate) were pretreated with GM2 $(0.1,1$ and $10 \mu \mathrm{M})$ or Dexa $(10 \mu \mathrm{M})$ at $37^{\circ} \mathrm{C}$ for $1 \mathrm{~h}$ and cotreated with TNF- $\alpha(10 \mathrm{ng} / \mathrm{ml})$ and IFN- $\gamma(10 \mathrm{ng} / \mathrm{ml})$ at $37^{\circ} \mathrm{C}$ for $6 \mathrm{~h}$. At the end of the in vivo experimental period, the back skins of the mice were collected and homogenized by a TissueLyser II (Qiagen $\mathrm{GmbH}$ ).

For cDNA synthesis, the RevertAid RT kit (Thermo Fisher Scientific, Inc.) was used as per the following conditions: $65^{\circ} \mathrm{C}$ for $5 \mathrm{~min}, 42^{\circ} \mathrm{C}$ for $60 \mathrm{~min}$ and $70^{\circ} \mathrm{C}$ for $5 \mathrm{~min}$. RT-qPCR was performed using the TB Green Premix Ex Taq (TIi RNaseH Plus; Takara Bio, Inc.). The primer sequences are listed in Table II.

The thermocycling conditions were as follows: $10 \mathrm{sec}$ at $95^{\circ} \mathrm{C}, 40$ cycles of $5 \mathrm{sec}$ at $95^{\circ} \mathrm{C}$ and $30 \mathrm{sec}$ at $60^{\circ} \mathrm{C}, 15 \mathrm{sec}$ at $95^{\circ} \mathrm{C}, 30 \mathrm{sec}$ at $60^{\circ} \mathrm{C}$ and $15 \mathrm{sec}$ at $95^{\circ} \mathrm{C}$. Quantification analysis was performed using the $2^{-\Delta \Delta \mathrm{Cq}}$ method (28). mRNA expression was normalized against glyceraldehyde 3-phosphate dehydrogenase for both the HaCaT cells and skin tissue, which were quantified by using the TP850 software (version 5.11; Takara Bio, Inc.).

Histological and immunohistochemical (IHC) analysis. The mice back skins were fixed with $10 \%$ formaldehyde at room temperature for $48 \mathrm{~h}$ and embedded in paraffin; $6-\mu \mathrm{m}$ sections were stained with toluidine blue (cat. no. 6586-04-5; Sigma-Aldrich; Merck KGaA) at room temperature for $30 \mathrm{sec}$ to observe the mast cells, hematoxylin and eosin (H\&E) at room temperature for $40 \mathrm{~min}$ or IHC (for MPO or CD4) for histological analysis. The epidermis and dermis of the tissues were observed under the HBO 100 light microscope (Carl Zeiss AG). The epidermal and dermal thickness were measured by a stage micrometer 10:100 lens (magnification, x200; Carl Zeiss AG), which was equipped on microscopic lens. The toluidine blue, H\&E and IHC-stained sections were observed under x200 magnification. IHC analysis was performed to detect the expression of MPO or CD4 in mice skin tissue. In brief, sections were deparaffinized in xylene, followed by treatment with graded ethanol solutions and rehydration in PBS. Sections were treated with $3 \%$ hydrogen peroxide for $5 \mathrm{~min}$, followed by microwave antigen retrieval at $95^{\circ} \mathrm{C}$ for $15 \mathrm{~min}$. Next, the slides were blocked with blocking buffer [1X PBS/5\% normal goat serum (cat. no. ab7481; Abcam)/0.05\% Tween-20] at room temperature for $1 \mathrm{~h}$. The slides were then incubated with rabbit monoclonal antibodies against MPO (1:100; cat. no. ab208670; Abcam) or CD4 (1:100; cat. no. ab183685; Abcam) at $4^{\circ} \mathrm{C}$ overnight. Subsequently, the slides were incubated with a secondary horseradish peroxidase-conjugated anti-rabbit IgG (1:500; cat. no. 7074S; Cell Signaling Technology, Inc.) at room temperature for $1 \mathrm{~h}$. Positive reaction was observed with 3,3'-diaminobenzidine (Vector Laboratories, Inc.; Maravai LifeSciences), and the slides were counterstained with hematoxylin at room temperature for $1 \mathrm{~min}$. The IHC-stained sections were observed under the HBO 100 light microscope (Carl Zeiss AG).

Western blotting. HaCaT cells $\left(1 \times 10^{6}\right.$ cells/well) were seeded in a 6-well plate and pretreated with GM2 $(10 \mu \mathrm{M})$ or Dexa $(10 \mu \mathrm{M})$ at $37^{\circ} \mathrm{C}$ for $1 \mathrm{~h}$ and then treated with TNF- $\alpha(10 \mathrm{ng} / \mathrm{ml})$ and IFN- $\gamma(10 \mathrm{ng} / \mathrm{ml})$ at $37^{\circ} \mathrm{C}$ for $15 \mathrm{~min}$. After stimulation, cells were washed twice with $1 \mathrm{ml}$ cold PBS, centrifuged at $1,200 \times \mathrm{g}$ at $4^{\circ} \mathrm{C}$ for $10 \mathrm{~min}$, resuspended in $400 \mu \mathrm{l}$ ice-cold 
Table II. Sequences of primer pairs for reverse transcription-quantitative PCR.

A, In vitro (Human)

\begin{tabular}{llc}
\hline Primer & \multicolumn{1}{c}{ Sequence $\left(5^{\prime} \rightarrow 3^{\prime}\right)$} & GenBank accession number \\
\hline CCL17 & F: GTTCGGACCCCAACAACAAG & NM_002987.3 \\
& R: TGGCTCCAGTTCAGACAAGG & NM_000576.3 \\
IL-1 $\beta$ & F: GCTGATGGCCCTAAACAGATGAA & \\
& R: TGAAGCCCTTGCTGTAGTGGTG & NM_001371096.1 \\
IL-6 & F: AAAGAGGCACTGGCAGAAAA & \\
& R: ATCTGAGGTGCCCATGCTAC & NM_000584.4 \\
IL-8 & F: GGTGCAGTTTTGCCAAGGAG & \\
GAPDH & R: TGCTTGAAGTTTCACTGGCATC & NM_002046.7 \\
& F: CGACCACTTTGTCAAGCTCA & \\
\hline
\end{tabular}

$\mathrm{B}$, In vivo (mouse)

\begin{tabular}{|c|c|c|}
\hline Primer & Sequence $\left(5^{\prime} \rightarrow 3^{\prime}\right)$ & GenBank accession number \\
\hline CXCL1 & $\begin{array}{l}\text { F: TGTGGGAGGCTGTGTTTGTA } \\
\text { R: ACGAGACCAGGAGAAACAGG }\end{array}$ & NM_008176.3 \\
\hline TNF- $\alpha$ & $\begin{array}{l}\text { F: GGCAGGTCTACTTTGGAGTCATTGC } \\
\text { R: ACATTCGAGGCTCCAGTGAATTCGG }\end{array}$ & NM_001278601.1 \\
\hline IL-17A & $\begin{array}{l}\text { F: TTTAACTCCCTTGGCGCAAAA } \\
\text { R: CTTTCCCTCCGCATTGACAC }\end{array}$ & NM_010552.3 \\
\hline IFN- $\gamma$ & $\begin{array}{l}\text { F: TCAAGTGGCATAGATGTGGAAGAA } \\
\text { R: TGGCTCTGCAGGATTTTCATG }\end{array}$ & NM_008337.4 \\
\hline IL-1 $\beta$ & $\begin{array}{l}\text { F: ATAACCTGCTGGTGTGTGAC } \\
\text { R: AGGTGCTGATGTACCAGTTG }\end{array}$ & NM_008361.4 \\
\hline IL-23 & $\begin{array}{l}\text { F: CATGGGGCTATCAGGGAGTA } \\
\text { R: AATAATGTGCCCCGTATCCA }\end{array}$ & NM_031252.2 \\
\hline GAPDH & $\begin{array}{l}\text { F: TGCTCCTCCCTGTTCCAGA } \\
\text { R: TACGGCCAAATCCGTTCACA }\end{array}$ & NM_008084.3 \\
\hline
\end{tabular}

F, forward; R, reverse; CXCL1, growth-regulated a protein; CCL17, C-C motif chemokine 17; TNF, tumor necrosis factor; IFN, interferon.

hypotonic buffer (10 $\mathrm{mM} \mathrm{HEPES} / \mathrm{KOH}, 2 \mathrm{mM} \mathrm{MgCl}, 0.1 \mathrm{mM}$ EDTA, $10 \mathrm{mM} \mathrm{KCl,} 1 \mathrm{mM}$ DTT and 0.5 mM PMSF; pH 7.9), left on ice for $10 \mathrm{~min}$, vortexed and centrifuged at $15,000 \mathrm{x} \mathrm{g}$ at $4^{\circ} \mathrm{C}$ for $5 \mathrm{~min}$. Then, the supernatant was used for the cytosolic proteins. After washing, the pelleted nuclei were resuspended in $50 \mu \mathrm{l}$ ice-cold lysis buffer (50 mM HEPES/KOH, $50 \mathrm{mM}$ $\mathrm{KCl}, 300 \mathrm{mM} \mathrm{NaCl}, 0.1 \mathrm{mM}$ EDTA, $10 \%$ glycerol, $1 \mathrm{mM}$ DTT and $0.5 \mathrm{mM}$ PMSF; pH 7.9), left on ice for $20 \mathrm{~min}$, vortexed and centrifuged at $15,000 \mathrm{x}$ g for $5 \mathrm{~min}$ at $4^{\circ} \mathrm{C}$; the supernatant was collected. The supernatant was used as the nuclear proteins.

The cytosolic and nuclear proteins were quantified using the Bradford protein assay (Bio-Rad Laboratories, Inc.). Proteins (10 $\mu \mathrm{g}$ for STAT1 and phospho-STAT1 ${ }^{\text {Thy701 }}, 30 \mu \mathrm{g}$ for $\mathrm{I} \kappa \mathrm{B} \alpha$ and $\mathrm{NF}-\kappa \mathrm{B}$ p65) were loaded into each well and separated via $10 \%$ SDS-PAGE. The separated proteins were then transferred to $0.45 \mu \mathrm{m}$ nitrocellulose membranes (Pall Life Sciences). The membranes were blocked with $3 \%$ bovine serum albumin (Sigma-Aldrich; Merck $\mathrm{KGaA}$ ) for $1 \mathrm{~h}$ at room temperature. Next, the membranes were incubated with the primary antibodies overnight at $4^{\circ} \mathrm{C}$, followed by incubation with the secondary antibodies at room temperature for $1 \mathrm{~h}$. Immunodetection was performed using G: Box Chemi XRQ (version 1.6.1.0; Syngene Europe) with a SuperSignal West Pico chemiluminescent substrate (Thermo Fisher Scientific, Inc.). $\beta$-actin and lamin B1 were used as the internal loading controls for the cytosolic and nuclear proteins, respectively. Primary antibodies against STAT1 (1:1,000; cat. no. 9172S), phospho-STAT1 ${ }^{\text {Th701 }}$ (1:1,000; cat. no. 9167S), IкB $\alpha$ (1:1,000; cat. no. 9242S) and NF- $\mathrm{KB}$ p65 (1:1,000; cat. no. 8242S) and secondary antibodies [horseradish peroxidase-conjugated anti-rabbit IgG (1:5,000; cat. no. 7074S) and anti-mouse IgG (1:5,000; cat. no. 7076S)] were purchased from Cell Signaling Technology, Inc. Primary antibodies against $\beta$-actin (1:1,000; cat. no. SC47778) and lamin B1 (1:1,000; cat. no. SC374015) were purchased from Santa Cruz Biotechnology, Inc.

Flow cytometry. After sacrifice, the spleen was weighed on a PAG214 analytical balance (Ohaus Corporation). Then, the 
mouse spleens were carefully ground using $70-\mu \mathrm{m}$ nylon cell strainers (Falcon; Corning Life Sciences) to obtain regular single cells. Red blood cells were removed by treating with the red blood cell lysis buffer twice, and the single cells were counted. Subsequently, the cells were stained using mouse CD4 PerCP-Cy ${ }^{\mathrm{TM}}$ 5.5-FITC-conjugated T helper (Th)1 (IFN- $\gamma$ ), CD4 PerCP-Cy ${ }^{\mathrm{TM}}$ 5.5-APC-conjugated Th2 (IL-4) or CD4 PerCP-Cy ${ }^{\mathrm{TM}}$ 5.5-PE-conjugated Th17 (IL-17A) phenotyping kit (BD Biosciences) as per the manufacturer's protocol. The fluorescence intensity was detected using a FACSCalibur flow cytometer (BD Biosciences), and the data were analyzed using BD CellQuest ${ }^{\mathrm{TM}}$ Pro software (BD Biosciences) to determine the percentage of $\mathrm{CD}^{+}$and gated IFN- $\gamma^{+}$plus IL-17A ${ }^{+}$ populations.

Statistical analyses. Statistical analyses were performed using Prism 8 software (GraphPad Software, Inc.). The treatment effects were analyzed using one-way analysis of variance followed by Dunnett's post hoc test. Additionally, PASI score data were analyzed using Kruskal-Wallis test followed by Dunn's multiple comparison test. Experiments were independently repeated in triplicate. $\mathrm{P}<0.05$ was considered to indicate a statistically significant difference.

\section{Results}

GM2 inhibits psoriasis-associated characteristics in an IMQ-induced mouse model. The clinical characteristics of psoriasis include scaling, erythema, dry skin, inflammatory keratosis and histological changes in the epidermal and dermal thickness (29). To assess the effects of GM2 on psoriasis-like skin inflammation, an experimental psoriasis mouse model was induced using IMQ cream.

The repeated application of IMQ exacerbated characteristics of psoriasis, including: i) Epidermis, dermis and skin thickness; ii) epidermal hyperplasia; iii) dry skin; and iv) immune cell infiltration. However, the oral administration of GM2 not only alleviated these characteristics of psoriasis in a dose-dependent manner, but also decreased the infiltration of MPO-related cells (Figs. 1A and S2A). Recently, GM2 has been demonstrated to have anti-allergic effects (17). Therefore, to investigate whether GM2 reduced the number of mast cells in IMQ-induced skin, toluidine blue-stained tissues were microscopically examined. The infiltration of mast cells into the skin was increased by IMQ, however, it was decreased by GM2 (Fig. S2B). In addition, GM2 inhibited the IMQ-induced infiltration of $\mathrm{CD}^{+}{ }^{+}$cells into the skin (Fig. S3). The IMQ-induced skin had increased epidermal, dermal and skin thickness when compared with that in the control group. However, the GM2-administered group exhibited decreased epidermis, dermis and skin thickness in a dose-dependent manner (Fig. 1B and C). Moreover, GM2 decreased IMQ-induced TEWL (Fig. 1D).

Psoriatic area and severity assessments primarily relied on the PASI scoring to investigate scaling, erythema and thickness (30). The continued application of IMQ increased the PASI score; however, the oral administration of GM2 alleviated the PASI score in a dose-dependent manner (Fig. 1E).

GM2 decreases inflammatory-related gene expression and serum levels. Several immune cells, including neutrophils and
$\mathrm{T}$ cells, infiltrate the site of the psoriatic lesion and exacerbate the condition by releasing inflammatory cytokines and chemokines (31). To evaluate the inhibitory effects of GM2 on the IMQ-induced inflammatory cytokines and chemokines, the expression levels of both were measured via RT-qPCR. The application of IMQ increased the expression of several cytokines and chemokines, including growth-regulated a protein (CXCL1), IL-1 $\beta$, IFN- $\gamma$, IL-17A, IL-23 and TNF- $\alpha$. However, GM2 alleviated the gene expression levels of these cytokines and chemokines (Fig. 2A).

To investigate the serum levels of the inflammatory-related proteins, the serum levels of MPO, TNF- $\alpha$ and IgG2a were measured using ELISA. The application of IMQ increased the serum levels of these proteins. However, their levels were reduced by GM2 in a dose-dependent manner (Fig. 2B).

GM2 inhibits the alteration of Th1 and Th17 cell populations in the spleen. The development of psoriasis is characterized by alterations in the polarization of the $\mathrm{T}$ cell population, primarily Th1 and Th17 cells (32). To assess whether GM2 could influence systemic immune responses, the weight of the spleen was measured and alterations in the psoriasis-associated T cell populations in the spleen were determined. IMQ-treated mice had increased spleen weights compared with those in the control group. However, the oral administration of GM2 significantly decreased the spleen weights (Fig. 3A). In addition, the population of $\mathrm{CD}^{+} \mathrm{IFN}-\gamma^{+} \mathrm{IL}-17 \mathrm{~A}^{+}$cells were elevated in the IMQ-induced mice. However, the oral administration of GM2 significantly decreased these cell numbers (Fig. 3B and C).

GM2 inhibits inflammatory gene expression by inhibiting the STAT1 and NF- $\kappa B$ signaling pathways in the keratinocytes. TNF- $\alpha$ and IFN- $\gamma$ increase the promotion of keratinocytes owing to the inflammatory environment of the skin and stimulate the production and the release of diverse inflammatory regulators (33). Therefore, TNF- $\alpha$ - and IFN- $\gamma$-activated keratinocytes were used in the present study.

The possible cytotoxicity of GM2 were initially evaluated by performing an MTT assay. GM2 did not exhibit cytotoxic effects on the keratinocytes at concentrations of up to $10 \mu \mathrm{M}$ (Fig. 4A). Therefore, the maximum concentration of $10 \mu \mathrm{M}$ was used for the in vitro experiments. The effects of GM2 on the production and release of inflammatory regulators in the TNF- $\alpha$ - and IFN- $\gamma$-stimulated keratinocytes were then evaluated. However, pretreatment with GM2 significantly reduced the expression of cytokines and chemokines, including C-C motif chemokine 17 (CCL17), IL-8, IL-6 and IL-1 $\beta$, in a dose-dependent manner compared with the TNF- $\alpha$ - and IFN- $\gamma$-stimulated group (Fig. 4B). In addition, GM2 significantly reduced the secretion of CCL17 and IL-6 in a dose-dependent manner compared with the TNF- $\alpha$ - and IFN- $\gamma$-stimulated group (Fig. 4C).

To investigate the inhibitory effects of GM2 on the activated keratinocytes, western blotting was performed. The TNF- $\alpha$ - and IFN- $\gamma$ stimulation not only activated STAT1 and NF- $\mathrm{NB}$, but also induced $\mathrm{I} \kappa \mathrm{B} \alpha$ degradation; however, GM2 significantly inhibited the phosphorylation of STAT1, the translocation of NF- $\mathrm{B}$ and the degradation of I $\kappa \mathrm{B} \alpha$ compared with the TNF- $\alpha$ - and IFN- $\gamma$-stimulated group (Fig. 4D). 
A

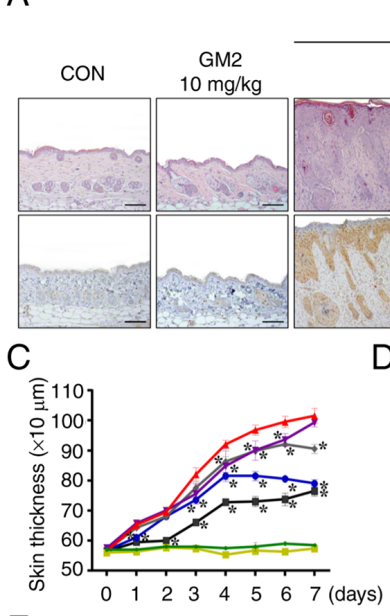

D
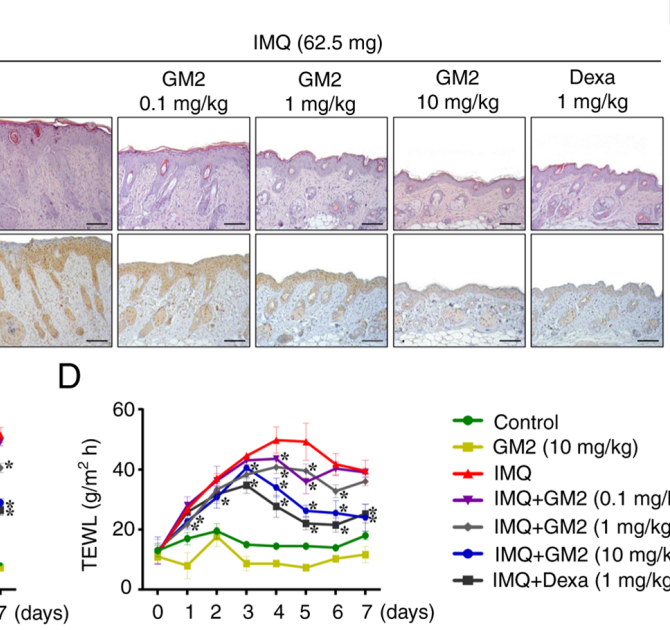

$\mathrm{B}$

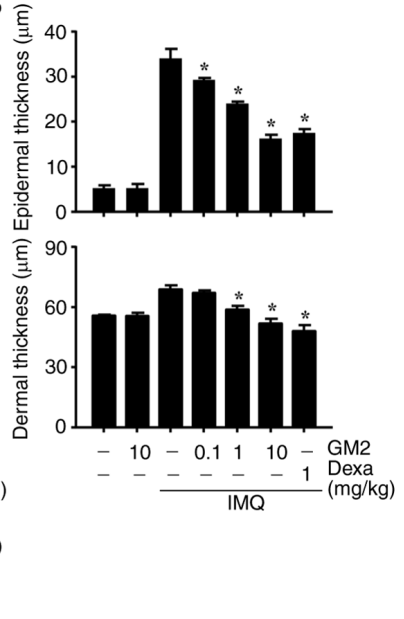

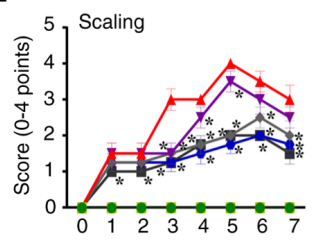
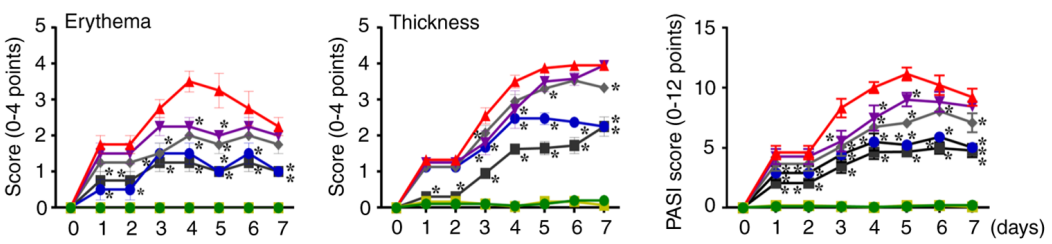

Figure 1. GM2 attenuates symptoms of psoriasis in an IMQ-induced mouse model. For histological observation, mouse tissue was obtained at 7 days. (A) The mice skin tissues were stained with hematoxylin and eosin or antibodies against myeloperoxidase for histological observation and for the determination of epidermal and dermal thickness and immune cell infiltration. Original magnification, x200; scale bar, $100 \mu \mathrm{m}$. (B) Epidermal and dermal thickness were measured using a stage micrometer under a brightfield microscope (magnification, x200). (C) Skin thickness. The skin thickness was measured $24 \mathrm{~h}$ after GM2 or Dexa application using a dial thickness gauge. (D) TEWL was measured $24 \mathrm{~h}$ after GM2 or Dexa application using a gpskin Barrier Light. (E) PASI score of the mice skin in different groups, including scaling, erythema and thickness (scale of 0-4 and total score were measured). The data are presented as the mean \pm standard error of the mean $(n=4)$. "P<0.05 vs. IMQ only group. GM2, gomisin M2; IMQ, imiquimod; Dexa, dexamethasone; TEWL, transepidermal water loss; PASI, Psoriasis Area Severity Index.

A
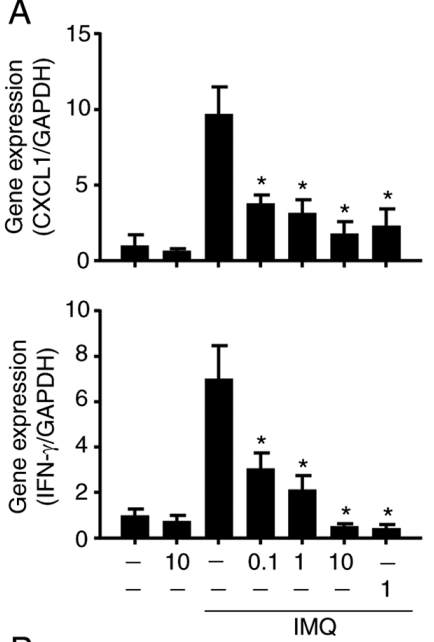

B

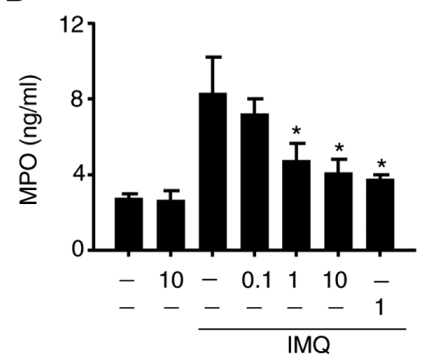

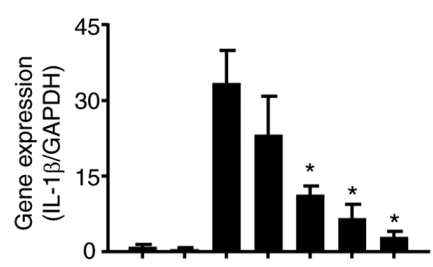
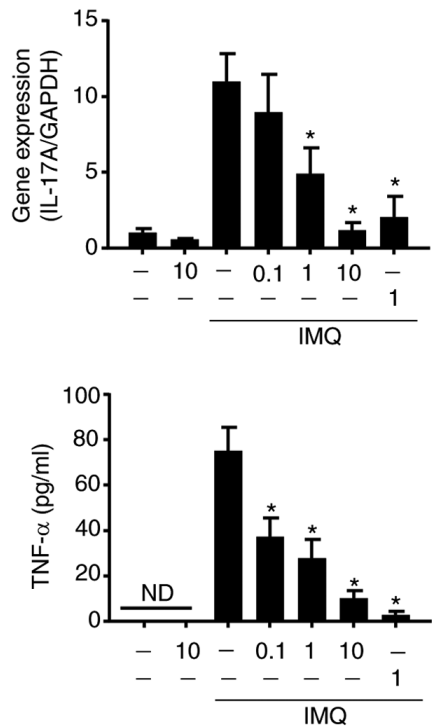
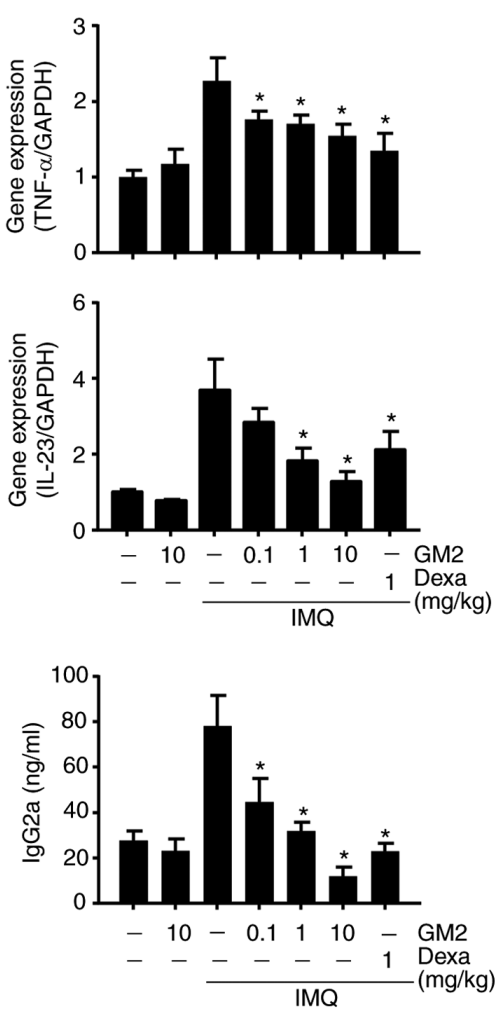

Figure 2. GM2 inhibits psoriasis-associated gene expression and serum levels. (A) mRNA expression was measured via reverse transcription-quantitative PCR and normalized to GAPDH. (B) MPO, TNF- $\alpha$ and IgG2a were measured using sandwich ELISA. The data are presented as the mean \pm standard error of the mean (n=4). "P<0.05 vs. IMQ only group. GM2, gomisin M2; GAPDH, glyceraldehyde 3-phosphate dehydrogenase; IgG2a, immunoglobulin G2a; MPO, myeloperoxidase; IMQ, imiquimod; Dexa, dexamethasone; CXCL1, growth-regulated a protein; TNF, tumor necrosis factor; IFN, interferon; ND, not detected. 
A

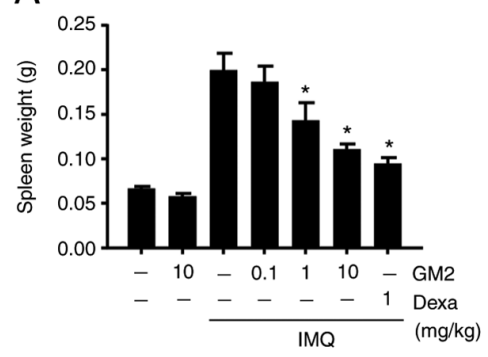

C

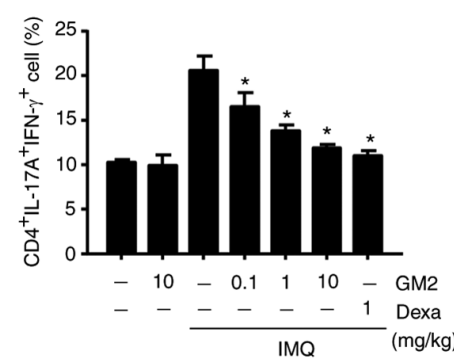

B
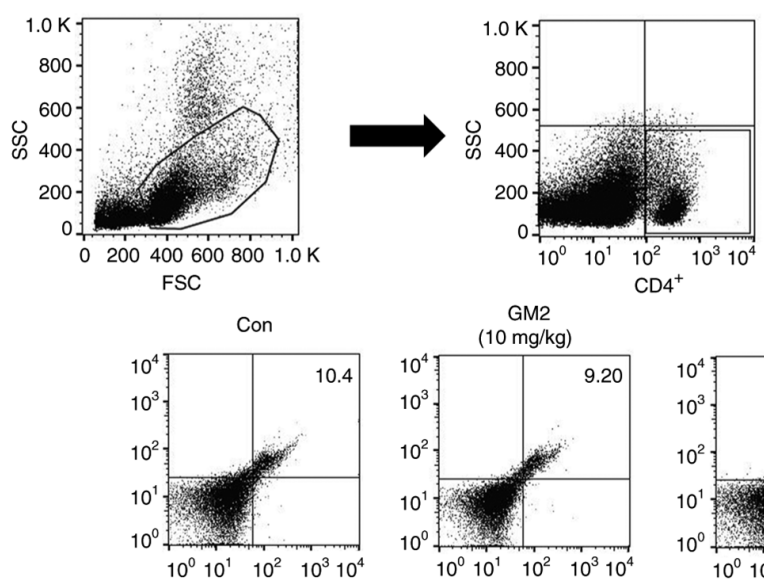

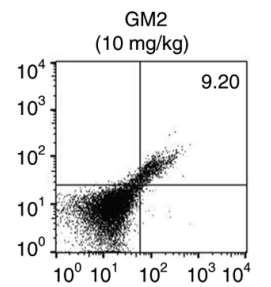

$\mathrm{IMQ}$

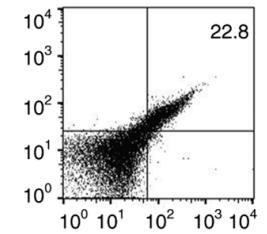

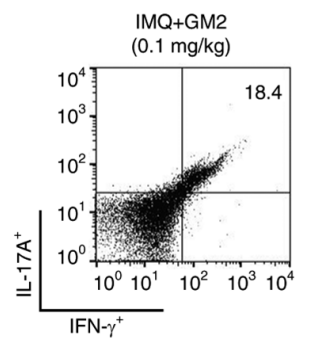
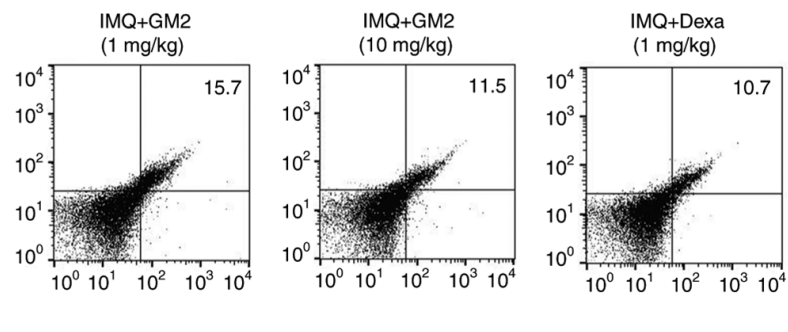

Figure 3. GM2 decreases Th1/Th17-cell population in the spleen. Spleens were obtained from each mouse and (A) weighed, and single cells were isolated. $(\mathrm{B}$ and $\mathrm{C})$ The number of cells was estimated using FACSCalibur. The data are presented as the mean \pm standard error of the mean $(\mathrm{n}=4)$. "P<0.05 vs. IMQ only group. GM2, gomisin M2; Th, T helper; IMQ, imiquimod; Dexa, dexamethasone; IFN, interferon.

A

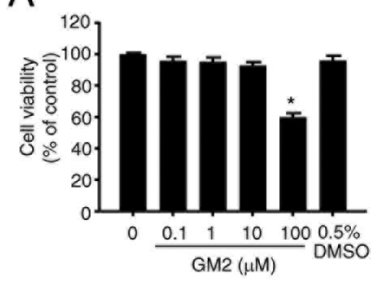

C

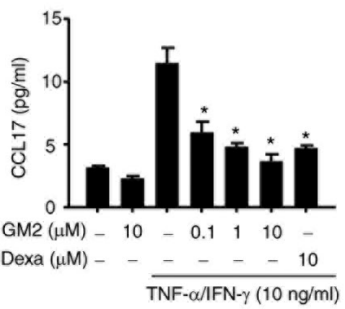

B

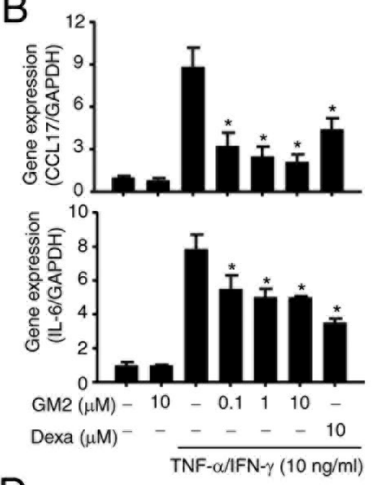

D

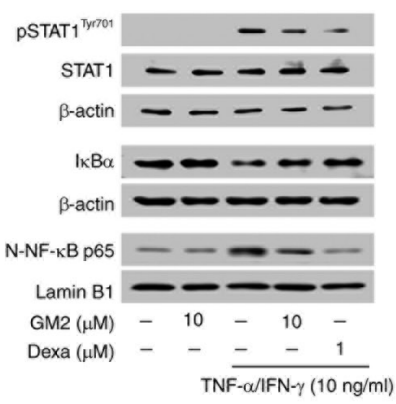

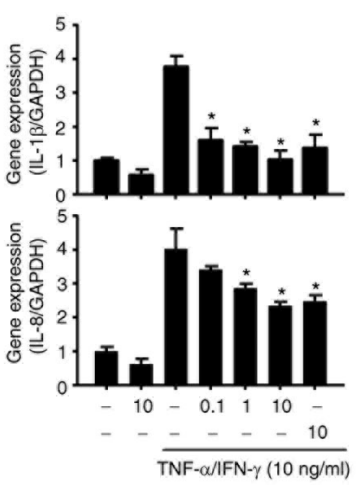
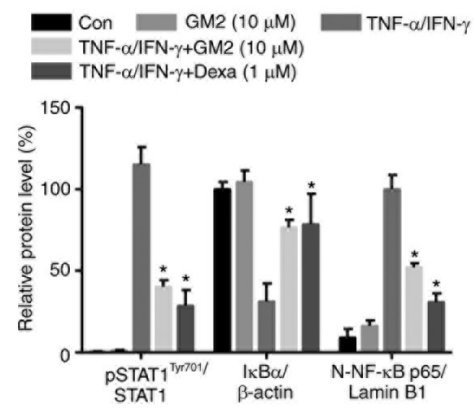

Figure 4. GM2 inhibits inflammatory mediators and the inflammatory signaling pathway in keratinocytes stimulated by TNF- $\alpha$ and IFN- $\gamma$. Cells were pretreated with GM2 or Dexa before stimulation with TNF- $\alpha(10 \mathrm{ng} / \mathrm{ml})$ and IFN- $\gamma(10 \mathrm{ng} / \mathrm{ml})$. (A) Viability of the HaCaT cells following GM2 treatment was determined using the 3-(4,5-dimethylthiazol-2-yl)-2,5-diphenyl tetrazolium bromide assay. (B) mRNA expression levels of CCL17, IL-1 $\beta$, IL-6 and IL-8 in the keratinocytes were measured via reverse transcription-quantitative PCR. (C) The cells were pretreated with GM2 or Dexa for $1 \mathrm{~h}$, followed by stimulation with TNF- $\alpha$ and IFN- $\gamma(10 \mathrm{ng} / \mathrm{ml})$ for $15 \mathrm{~h}$. The secretory protein levels of IL-6 and CCL17 were measured by ELISA. (D) The cells were pretreated with GM2 or Dexa for $1 \mathrm{~h}$ and subsequently with TNF- $\alpha$ and IFN- $\gamma$ for $15 \mathrm{~min}$. The phosphorylation of STAT1, degradation of IkB $\alpha$ and nuclear translocation of NF- $\mathrm{KB}$ p 65 were analyzed by western blotting. $\beta$-actin and lamin B1 were used as loading controls, and the band intensity was semi-quantified using ImageJ software. The data are presented as the mean \pm standard error of the mean $(n=3)$. " $\mathrm{P}<0.05$ vs. TNF- $\alpha$ - and IFN- $\gamma$-stimulated group. GM2, gomisin M2; Dexa, dexamethasone; TNF, tumor necrosis factor; IFN, interferon; CCL17, C-C motif chemokine 17; p, phosphorylated; STAT1, signal transducers and activators of transcription $1 ; \mathrm{NF}-\kappa \mathrm{B}$, nuclear factor- $\kappa \mathrm{B}$. 


\section{Discussion}

The annual incidence of psoriasis is increasing and is aggravated by various factors, such as air pollution, smoking, mechanical stress, dyslipidemia and hypertension $(34,35)$. The topical application of corticosteroids has been used as the main treatment for psoriasis. However, the long-term application of corticosteroids is not advisable owing to their diverse side effects, including atrophy, hyperpigmentation, hypercoagulable state and dyslipidemia (22). Therefore, the attention of the research community has turned toward natural products based on traditional medicine (36). These products are rich in bioactive compounds that encompass a wider chemical space than the common synthetic small-molecule libraries (37).

The fruits of S. chinensis have long been used in traditional medicine in China, Japan and Korea to treat diseases such as asthma and diabetes $(38,39)$. Moreover, $S$. chinensis has been certified as a safe nutritional ingredient by the European Food Safety Agency, and its fruit has been reported to have diverse pharmacological properties, including antioxidant, anti-inflammatory and antiallergic effects $(17,40)$. GM2 extracted from $S$. chinensis has also been documented to exert various pharmacological effects, including preventing liver damage and reducing cancer cell proliferation $(18,19,41)$. Based on these benefits, the present study explored the inhibitory effects of GM2 on IMQ-induced psoriasis-like skin inflammation and on TNF- $\alpha$ - and IFN- $\gamma$-stimulated keratinocytes after the purity of the GM2 isolated from $S$. chinensis was determined.

Psoriasis is characterized by prominent skin inflammation involving neutrophils, which can potentiate $\mathrm{T}$ cell-associated inflammation (42). T cells and mast cells can infiltrate psoriatic lesions and accelerate the development of psoriasis $(43,44)$. In addition, neutrophils express a number of different cytokines and chemokines, including CXCL1, IL-17, TNF- $\alpha$ and IFN- $\gamma$, which can accelerate the progress of psoriasis (45). Therefore, controlling the infiltration of neutrophils in psoriatic lesions and in the serum is important for the treatment of psoriasis. In the current study, MPO was used as the marker for neutrophils as it is a major protein found in neutrophilic granules (46). Thus, reducing the MPO levels in psoriatic skin and in the serum may be a suitable approach to reduce skin inflammation.

The present findings showed that GM2 decreased the infiltration of MPO-associated cells in the psoriatic lesions as well as the levels of MPO in the serum. In addition, the mRNA expression levels of neutrophil-related cytokines and chemokines, such as CXCL1, IL-1 $\beta$, IL-17A, IL-23, TNF- $\alpha$ and IFN- $\gamma$, were decreased in the lesions. These results suggested that GM2 alleviated psoriasis-like skin inflammation by inhibiting the infiltration of neutrophils and neutrophil-related inflammatory factors. In addition, IgG2a and TNF- $\alpha$ levels have been found to be abnormally elevated in the serum of patients with psoriasis $(47,48)$. The current findings indicated that GM2 reduced IgG2a and TNF- $\alpha$ in the serum of the IMQ-treated mice. Therefore, GM2 may be able to alleviate psoriasis by controlling the levels of inflammatory-related factors in the serum. Additionally, this study showed that GM2 inhibited the infiltration of mast cell and $\mathrm{CD}^{+}$cells. This suggested that GM2 alleviated characteristics of psoriasis by inhibiting skin penetration of psoriasis-related cells. Furthermore, as skin hydration is an index of skin barrier function in IMQ-induced psoriasis-like skin (49), TEWL was measured in the present study using the gpskin barrier light. These results showed that TEWL was increased in IMQ-induced skin, however, it was reduced by GM2. This result indicated that GM2 had a beneficial effect on increasing moisture in the skin.

Several reports have provided evidence that Th1 and Th17 cells are increased in psoriasis $(32,50)$. Th1 cells are considered to be the major factors in the development of psoriasis and are known to be mainly involved in the early stages of the disease (46). Th17 cells also play an important role in IL-17 production and psoriasis maintenance (46). Therefore, the inhibition of these cells associated with inflammation is important for suppressing the symptoms of psoriasis. GM2 significantly suppressed the number of Th1 and Th17 cells. These findings implied that GM2 exerts its anti-psoriasis effects by blocking Th1 and Th17 cell infiltration during pathogenesis.

The current study evaluated the effects of GM2 on activated keratinocytes, which are significant sources of cytokines that can aggravate psoriasis development (29). TNF- $\alpha$ and IFN- $\gamma$ induce the production of various proinflammatory cytokines by activating transcription factors, including STAT1 and NF- $\mathrm{KB}$, in the keratinocytes. The induced inflammatory cytokines can exacerbate the skin lesions $(51,52)$. In the present study, it was established that GM2 decreased the expression levels of inflammatory-related genes and the levels of secretory proteins in the activated keratinocytes. In addition, GM2 inhibited the phosphorylation of STAT1 and the translocation of NF- $\kappa$ B in TNF- $\alpha$ - and IFN- $\gamma$-activated keratinocytes. Therefore, the anti-inflammatory effects of GM2 on TNF- $\alpha$ - and IFN- $\gamma$-treated keratinocytes may be exerted through a reduction in the production of cytokines and chemokines by blocking the phosphorylation of STAT1 and the translocation of NF- $\mathrm{\kappa B}$.

Collectively, these results indicated that a natural compound containing GM2 could serve as a useful supplement for treating psoriasis. However, further experiments are required to explore the long term effects of GM2 in psoriasis-like skin inflammation.

\section{Acknowledgements}

Not applicable.

\section{Funding}

This work was supported by the National Research Foundation of Korea grants funded by the Korean government (grant nos. 2019R1C1C1005172, 2019R1A2B5B01069444, 2019M3A9H1103690, 2017M3A9G8083382 and 2020M3A9D3038894).

\section{Availability of data and materials}

The datasets used and/or analyzed during the current study are available from the corresponding author on reasonable request.

\section{Authors' contributions}

NK performed the experiments and wrote the original draft of the manuscript. SL conceived the research and analyzed 
the data. JK performed the experiments. TKK designed the methodology. DK and SHK performed the analysis and interpretation of data, and revised the manuscript. DK and SHK confirm the authenticity of all the raw data. All authors have read and approved the final manuscript.

\section{Ethics approval and consent to participate}

The study was conducted according to the guidelines of the Public Health Service Policy on the Humane Care and Use of Laboratory Animals, and approved by the Institutional Animal Care and Use Committee of Kyungpook National University (approval no. KNU-2019-0001-5; Daegu, Korea).

\section{Patient consent for publication}

Not applicable.

\section{Competing interests}

The authors declare that they have no competing interests.

\section{References}

1. Stockenhuber K, Hegazy AN, West NR, Ilott NE, Stockenhuber A, Bullers SJ, Thrnton EE, Arnold IC, Tucci A, Waldmann H, et al: Foxp $^{+} \mathrm{T}$ reg cells control psoriasiform inflammation by restraining an IFN-I-driven $\mathrm{CD}^{+} \mathrm{T}$ cell response. J Exp Med 215: 1987-1998, 2018.

2. Parisi R, Iskandar IYK, Kontopantelis E, Augustin M, Griffiths CEM and Ascroft DM; Global Psoriasis Atlas: National, regional, and worldwide epidemiology of psoriasis: Systematic analysis and modelling study. BMJ 369: m1590, 2020.

3. Danielsen K, Olsen AO, Wilsgaard T and Furberg AS: Is the prevalence of psoriasis increasing? A 30-year follow-up of a population-based cohort. Br J Dermatol 168: 1303-1310, 2013.

4. Kim WB, Jerome D and Yeung J: Diagnosis and management of psoriasis. Can Fam Physician 63: 278-285, 2017.

5. Mrowietz U and Domm S: Systemic steroids in the treatment of psoriasis: What is fact, what is fiction? J Eur Acad Dermatol Venereol 27: 1022-1025, 2013

6. Ghasemian M, Owlia S and Owlia MB: Review of anti-inflammatory herbal medicines. Adv Pharmacol Sci 2016: 9130979, 2016.

7. Zhao J, Di T, Wang Y, Wang Y, Liu X, Liang D and Li P: Paeoniflorin inhibits imiquimod-induced psoriasis in mice by regulating Th17 cell response and cytokine secretion. Eur J Pharmacol 772: 131-143, 2016.

8. Gallais Sérézal I, Hoffer E, Ignatov B, Martini E, Zitti B, Ehrström M and Eidsmo L: A skewed pool of resident T cells triggers psoriasis-associated tissue responses in never-lesional skin from patients with psoriasis. J Allergy Clin Immunol 143 $1444-1454,2019$.

9. Li L, Huang L, Vergis AL, Ye H, Bajwa A, Narayan V, Striter RM, Rosin DL and Okusa MD: IL-17 produced by neutrophils regulates IFN-gamma-mediated neutrophil migration in mouse kidney ischemia-reperfusion injury. J Clin Invest 120: 331-342, 2010.

10. Hawkes JE, Yan BY, Chan TC and Krueger JG: Discovery of the IL-23/IL-17 signaling pathway and the treatment of psoriasis. J Immunol 201: 1605-1613, 2018.

11. Lee B, Bae EA, Trinh HT, Shin YW, Phuong TT, Bae KH and Kim DH: Inhibitory effect of schizandrin on passive cutaneous anaphylaxis reaction and scratching behaviors in mice. Biol Pharm Bull 30: 1153-1156, 2007.

12. Kim H, Ahn YT, Kim YS, Cho SI and An WG: Antiasthmatic effects of schizandrae fructus extract in mice with asthma. Pharmacogn Mag 10 (Suppl 1): S80-S85, 2014.

13. Szopa A, Ekiert R and Ekiert H: Current knowledge of Schisandra chinensis (Turcz.) Baill. (Chinese magnolia vine) as a medicinal plant species: A review on the bioactive components, pharmacological properties, analytical and biotechnological studies. Phytochem Rev 16: 195-218, 2017.
14. Chae HS, Kang OH, Oh YC, Choi JG, Keum JH, Kim SB, Kim YS, Mun SH, Shin DW, Han SH and Kwon DY: Gomisin $\mathrm{N}$ has anti-allergic effect and inhibits inflammatory cytokine expression in mouse bone marrow-derived mast cells. Immunopharmacol Immunotoxicol 33: 709-713, 2011.

15. Opletal L, Sovová H and Bártlová M: Dibenzo[a,c]cyclooctadiene lignans of the genus Schisandra: Importance, isolation and determination. J Chromatogr B Analyt Technol Biomed Life Sci 812: 357-371, 2004.

16. Korkina L, Kostyuk V, De Luca C and Pastore S: Plant phenylpropanoids as emerging anti-inflammatory agents. Mini Rev Med Chem 11: 823-835, 2011

17. Dhakal H, Lee S, Kim EN, Choi JK, Kim MJ, Kang J, Choi YA, Baek MC, Lee B, Lee HS, et al: Gomisin M2 inhibits mast cell-mediated allergic inflammation via attenuation of FceRI-mediated Lyn and Fyn activation and intracellular calcium levels. Front Pharmacol 10: 869, 2019.

18. Chen M, Kilgore N, Lee KH and Chen DF: Rubrisandrins A and $\mathrm{B}$, lignans and related anti-HIV compounds from Schisandra rubriflora. J Nat Prod 69: 1697-1701, 2006.

19. Hou X, Deng J, Zhang Q, Wang D, Kennedy D, Quinn RJ and Feng Y: Cytotoxic ethnic Yao medicine Baizuan, leaves of Schisandra viridis A. C. Smith. J Ethnopharmacol 194: 146-152, 2016.

20. Li F, Zhang T, Sun H, Gu H, Wang H, Su X, Li C, Li B, Chen R and Kang J: A new nortriterpenoid, a sesquiterpene and hepatoprotective lignans isolated from the fruit of Schisandra chinensis. Molecules 22: 1931, 2017.

21. Public Health Service: Public health service policy on humane care and use of laboratory animals, US Department of Health and Human Services. NIH publication No. 15-8013, pp7-25, 2015.

22. Uva L, Miguel D, Pinheiro C, Antunes J, Cruz D, Ferreira J and Filipe P: Mechanisms of action of topical corticosteroids in psoriasis. Int J Endocrinol 2012: 561018, 2012.

23. Araki-Sasaki K, Katsuta O, Mano H, Nagano T and Nakamura M: The effects of oral and topical corticosteroid in rabbit corneas. BMC Ophthalmol 16: 160, 2016.

24. Samtani MN and Jusko WJ: Comparison of dexamethasone pharmacokinetics in female rats after intravenous and intramuscular administration. Biopharm Drug Dispos 26: 85-91, 2005.

25. Jeong NH, Lee S, Choi JK, Choi YA, Kim MJ, Lee HS, Shin TY, Jang YH, Song KS and Kim SH: Polyozellin alleviates atopic dermatitis-like inflammatory and pruritic responses in activated keratinocytes and mast cells. Biomed Pharmacother 122: 109743, 2020.

26. Li Q, Liu W, Gao S, Mao Y and Xin Y: Application of imiquimod-induced murine psoriasis model in evaluating interleukin-17A antagonist. BMC Immunol 22: 11, 2021.

27. Lim JS, Kim JY, Lee S, Choi JK, Kim EN, Choi YA, Jang YH, Jeong GS and Kim SH: Bakuchicin attenuates atopic skin inflammation. Biomed Pharmacother 129: 110466, 2020.

28. Livak KJ and Schmittgen TD: Analysis of relative gene expression data using real-time quantitative PCR and the 2(-Delta Delta C(T)) method. Methods 25: 402-408, 2001.

29. Lowes MA, Suárez-Fariñas M and Krueger JG: Immunology of psoriasis. Annu Rev Immunol 32: 227-255, 2014.

30. Feldman SR and Krueger GG: Psoriasis assessment tools in clinical trials. Ann Rheum Dis 64 (Suppl 2): ii65-ii73, 2005.

31. Chiang CC, Cheng WJ, Korinek M, Lin CY and Hwang TL: Neutrophils in psoriasis. Front Immunol 10: 2376, 2019.

32. Furiati SC, Catarino JS, Silva MV, Silva RF, Estevam RB, Teodoro RB, Pereira SL, Ataide M, Rodrigues V Jr and Rodrigues DBR: Th1, Th17, and Treg responses are differently modulated by TNF- $\alpha$ inhibitors and methotrexate in psoriasis patients. Sci Rep 9: 7526, 2019.

33. Bhattacharjee O, Ayyangar U, Kurbet AS, Ashok D and Raghavan S: Unraveling the ECM-immune cell crosstalk in skin diseases. Front Cell Dev Biol 7: 68, 2019.

34. Schonmann Y, Ashcroft DM, Iskandar IYK, Parisi R, Sde-Or S Comaneshter D, Batat E, Shani M, Vinker S, GriffithsCEM and Cohen AD: Incidence and prevalence of psoriasis in Israel between 2011 and 2017. J Eur Acad Dermatol Venereol 33: 2075-2081, 2019

35. Kamiya K, Kishimoto M, Sugai J, Komine M and Ohtsuki M: Risk factors for the development of psoriasis. Int J Mol Sci 20: 4347, 2019.

36. Meng S, Lin Z, Wang Y, Wang Z, Li P and Zheng Y: Psoriasis therapy by Chinese medicine and modern agents. Chin Med 13: $16,2018$.

37. Atanasov AG, Zotchev SB and Dirsch VM; International Natural Product Sciences Taskforce, Supuran CT: Natural products in drug discovery: Advances and opportunities. Nat Rev Drug Discov 20: 200-216, 2021. 
38. Kim EJ, Jang M, Lee MJ, Choi JH, Lee SJ, Kim SK, Jang DS and Cho IH: Schisandra chinensis stem ameliorates 3-nitropropionic acid-induced striatal toxicity via activation of the Nrf2 pathway and inhibition of the MAPKs and NF- $\kappa$ B pathways. Front Pharmacol 8: 673, 2017

39. Panossian A and Wikman G: Pharmacology of Schisandra chinensis Bail.: An overview of Russian research and uses in medicine. J Ethnopharmacol 118: 183-212, 2008.

40. Szopa A, Barnaś M and Ekiert H: Phytochemical studies and biological activity of three Chinese Schisandra species (Schisandra sphenanthera, Schisandra henryi and Schisandra rubriflora): Current findings and future applications. Phytochem Rev 18: 109-128, 2019.

41. Yang Y, Hao E, Pan X, Tan D, Du Z, Xie J, Hou X, Deng J and Wei K: Gomisin M2 from Baizuan suppresses breast cancer stem cell proliferation in a zebrafish xenograft model. Aging (Albany NY) 11: 8347-8361, 2019.

42. Tokuyama M and Mabuchi T: New treatment addressing the pathogenesis of psoriasis. Int J Mol Sci 21: 7488, 2020.

43. Siiskonen $\mathrm{H}$ and Harvima I: Mast cells and sensory nerves contribute to neurogenic inflammation and pruritus in chronic skin inflammation. Front Cell Neurosci 13: 422, 2019.

44. Diani M, Altomare G and Reali E: T helper cell subsets in clinical manifestations of psoriasis. J Immunol Res 2016: 7692024, 2016.

45. Ogawa E, Sato Y, Minagawa A and Okuyama R: Pathogenesis of psoriasis and development of treatment. J Dermatol 45: 264-272, 2018.

46. Odobasic D, Kitching AR and Holdsworth SR: Neutrophilmediated regulation of innate and adaptive immunity: The role of myeloperoxidase. J Immunol Res 2016: 2349817, 2016.
47. Dilek N, Dilek AR, Taşkın Y, Erkinüresin T, Yalçın Ö and Saral Y: Contribution of myeloperoxidase and inducible nitric oxide synthase to pathogenesis of psoriasis. Postepy Dermatol Alergol 33: 435-439, 2016.

48. Kyriakou A, Patsatsi A, Vyzantiadis TA and Sotiriadis D: Serum levels of TNF- $\alpha$, IL-12/23p40, and IL-17 in plaque psoriasis and their correlation with disease severity. J Immunol Res 2014: $467541,2014$.

49. Wallen-Russell C: Is there a relationship between transepidermal water loss and microbial biodiversity on the skin? Cosmetics 6 : $18,2019$.

50. Zhou F, Zhu Z, Gao J, Yang C, Wen L, Liu L, Zuo X, Zheng X, Shi Y, Zhu C, et al: NFKB1 mediates Th1/Th17 activation in the pathogenesis of psoriasis. Cell Immunol 331: 16-21, 2018.

51. Gröne A: Keratinocytes and cytokines. Vet Immunol Immunopathol 88: 1-12, 2002.

52. Wang L, Zhao Y, Liu Y, Akiyama K, Chen C, Qu C, Jin Y and Shi S: IFN- $\gamma$ and TNF- $\alpha$ synergistically induce mesenchymal stem cell impairment and tumorigenesis via NFKB signaling. Stem Cells 31: 1383-1395, 2013. International (CC BY-NC-ND 4.0) License. 